\title{
As inovações biotecnológicas sob as lentes da autodeterminação ecológica para a sustentabilidade
}

\author{
The innovations biotechnological on the lenses of the self-determination ecological \\ towards sustainability
}

Pedro Accioly de Sá Peixoto Neto*

\section{Resumo}

\begin{abstract}
Este trabalho tem por objetivo analisar as inovações biotecnológicas sob as lentes da autodeterminação ecológica auxiliada pelo imperativo da sustentabilidade. Para tanto, inicialmente, será definido o campo das inovações biotecnológicas e sua apropriação como ativo da biodiversidade face aos imperativos da sustentabilidade. Num segundo momento, serão investigados os contornos da autodeterminação ecológica e as conformações jurídicas, como diretrizes de decisões regulatórias no emprego dessas inovações biotecnológicas, com especial destaque para as relacionadas com os organismos geneticamente modificados para a agricultura. O que perpassa, obrigatoriamente, pela valorização não somente da economia, mas, também, das crenças e valores de cada povo, que, com o uso da autodeterminação ecológica, fará suas escolhas dentro de sua tolerância ao risco.
\end{abstract}

Palavras-chave: Autodeterminação ecológica. Inovações Biotecnológicas. Sustentabilidade. Sociedade do risco. Propriedade industrial.

\section{Abstract}

This work aims to analyze biotechnological innovations through the lens of self-determination ecological, aided by the imperative of sustainability. To do so, it will initially set the field of biotechnological innovations and their ownership as an asset of biodiversity, given the imperatives of sustainability. In a second step we will investigate the contours of ecological self-determination and the legal conformations, as guidelines of regulatory decisions employing these biotechnological innovations, with special emphasis on those related to genetically modified organisms in agriculture. What permeates necessarily the valuation, not only economic, but also the beliefs and values of each people, which, in the use of the ecological self-determination will make their choices within your risk tolerance.

Keywords: Ecological self-determination. Biotechnological innovations. Sustainability. Risk society. Industrial property.

\section{Introdução}

O desenvolvimento da biotecnologia agrícola e da engenharia genética tem gerado debates acirrados sobre seus reais contributos para a sociedade pós-moderna, tendo em vista que cresce, de modo significativo, a necessidade humana por alternativas à produção alimentar, dentro de padrões cada vez mais exigentes de biossegurança e de respeito aos valores ambientais de desenvolvimento sustentável, nem sempre plenamente satisfeitos pelas novas tecnologias.

Doutor em Direito pela Universidade de Coimbra (UC) - Portugal. Mestre em Direito pela Universidade de Coimbra (UC) - Portugal. Advogado e Engenheiro Agrônomo. Professor adjunto III da Universidade Federal de Alagoas (UFAL). Pesquisador membro do Grupo de Pesquisa Direito Privado e Contemporaneidade, da Faculdade de Direito e do Grupo de Pesquisa Biotecnologia de Plantas e de Microrganismos Endofíticos, ligado ao Instituto de Química e Biotecnologia, ambos da Universidade Federal de Alagoas. Coimbra - Portugal. E-mail: peaccioly@gmail.com. 
É diante desse debate que surge a polêmica questão dos transgênicos_ou organismos geneticamente modificados $(\mathrm{OGMs})^{1}$ - de plantas cultivadas para o fornecimento de alimentos importantes para a "mesa pós-moderna" nas mais diversas partes do mundo. Muitas vezes, ocorre sem ser dada a devida informação para os consumidores sobre seus potenciais riscos para a saúde humana e/ou ambiental, acabando por atingir direitos humanos dos mais basilares, com ênfase nos direitos à vida e à alimentação de qualidade, dentro de padrões de biossegurança rígidos, o que, por sua vez, não poderá excluir suas contribuições para o aumento da oferta de alimentos.

Como consequência, existe um campo ainda vasto para a análise jurídica com um olhar para além, dentro de um contexto de significativa complexidade, uma vez que se está diante de valores jurídicos que se assentam nas premissas científicas da segurança ambiental e alimentar, inclusive adentrando em questões de cunho ético-jurídico, como o respeito à autodeterminação ecológica de cada povo, sem a interferência de uma visão meramente economicista, reducionista, incapaz de solucionar tal problemática, tanto das sociedades mais igualitárias quanto das menos igualitárias, na direção da preservação do valor maior da sustentabilidade para as gerações presentes e futuras. ${ }^{2}$

Desse modo, o presente artigo avaliará a possibilidade da autodeterminação ecológica para as inovações biotecnológicas tuteladas pelos institutos do direito da propriedade industrial, perante a possibilidade de apropriação de ativos da biodiversidade e que devem estar sujeitas ao balizamento jurídico-ambiental de uma alimentação saudável e à preservação do bem ambiental, ambos integrantes do interesse da sociedade. Estes são a base para a construção de um desenvolvimento fundado na sustentabilidade em curto, médio e longo prazo, o que contará com o suporte do princípio jurídico da precaução como verdadeiro filtro diante das incertezas nos campos jurídico e científico, sempre com as lentes de uma sustentabilidade fundada na valorização da autodeterminação ecológica, sem olvidar os aspectos positivos quanto à geração de invenções biotecnológicas vegetais, úteis para a melhoria da competitividade e agregação de valor, além de plantas com maior potencial nutritivo e produtoras de compostos bioativos.

Na primeira parte deste trabalho, serão analisadas as inovações biotecnológicas e sua possibilidade de apropriação, enquanto ativo estratégico para a competitividade, em face do imperativo maior da sustentabilidade. Na segunda parte, serão avaliadas a autodeterminação ecológica dos povos e suas relações dentro do campo das inovações biotecnológicas, estas especialmente balizadas pela necessidade de respeito ao desenvolvimento sustentável como um categórico maior do direito de autodeterminação de cada povo, com suas escolhas político-jurídicas internalizadas por meio das políticas públicas de fomento à inovação tecnológica da biodiversidade.

\section{As inovações biotecnológicas e sua apropriação como ativo da biodiversidade no imperativo da sustentabilidade}

A necessidade humana de superação das adversidades permitiu que novas invenções fossem gradualmente desenvolvidas, o que causou grande impacto no modo de vida de milhões de pessoas e também sobre a forma como podem ser visualizadas tais conquistas do intelecto, gerando níveis maiores de conforto, bem-estar e até acúmulo de riquezas para as sociedades que as dominam.

\footnotetext{
Para fins deste trabalho serão utilizados como sinônimos os termos transgênicos e organismos geneticamente modificados (OGMs), apesar de que se pode separar os dois, visto que todo OGM será um transgênico, mas nem todo transgênico será um OGM, pois na natureza pode ocorrer a transferência de genes de um ser vivo para outro, como no caso de algumas bactérias que transferem parte de seu material genético para certas espécies de plantas, sem intervenção humana direta. Mas, como será dado ênfase, quase que exclusivamente, para as plantas que sofreram intervenções específicas pelo homem, então não será adotada esta diferença.

2 Entender as sociedades mais igualitárias como aquelas que já possuem uma menor desigualdade social, com um nível médio educacional apresentando maior número de anos de escolaridade e com índice de desenvolvimento humano (IDH) muito elevado, enquadrando-se no estrado mais exigente e que tendem a fazer escolhas que acabam por exigir padrões mais altos de qualidade de alimentos, o que implica controle do uso de agrotóxicos, bem como que aqueles sejam mais nutritivos e até com boa estética. Em oposição, as sociedades menos igualitárias apresentam um IDH num estrado mais baixo e com maiores problemas sociais e econômicos. Esta separação é importante, pois o IDH representa a segunda geração de índices de avaliação de desenvolvimento econômico e social, e leva em consideração importantes indicadores ligados à educação e longevidade, dentre outros que podem dialogar com sucesso, diante da sustentabilidade (BRAGA, 2006, p. 50).
} 
Dentre essas tecnologias, destacam-se aquelas relacionadas com um campo tecnológico de grande potencial em diversas áreas estratégicas para a sobrevivência humana, com realce para as biotecnologias, que podem ser empregadas desde a produção de medicamentos, vacinas, alimentos processados, até, recentemente, no setor agrícola, sendo essas tais criações responsáveis pelo rompimento de importantes barreiras tradicionais na evolução dos seres vivos, com repercussões significativas para certos bens jurídicos da mais elevada hierarquia nos diversos ordenamentos jurídicos internos, despertando forte clamor nas esferas internacionais.

Grandes foram os avanços que as biotecnologias promoveram para a realização do progresso científico e tecnológico em diversas áreas importantes, com repercussões desde a saúde pública até o agronegócio. Sendo responsáveis pelo surgimento e fortalecimento de grandes estruturas empresariais transnacionais que, pela pujança econômica gerada pelo setor, sem uma devida estrutura de regulação administrativa, ${ }^{3}$ podem causar distorções contrárias ao interesse social, o qual deve sempre pautar os rumos das invenções biotecnológicas. Esta posição também é adotada no plano interno pelo constituinte originário brasileiro, no art. $5^{\circ}$, inciso XXIX, da Constituição Brasileira de 1988 (CFB/1988), ${ }^{4}$ que, de modo expresso, determina a conformação dos institutos jurídicos de viés inovativo àquele valor constitucional.

Importa considerar que o desenvolvimento de tecnologias a partir da biodiversidade será sempre um grande desafio, principalmente para os países em desenvolvimento, tendo em vista que, apesar de serem significativamente ricos em recursos genéticos, ainda possuem sérios problemas quanto à sua transformação em biotecnologias por empresas nacionais, seja pela insuficiência que tais firmas possuem quanto ao domínio de pesquisas e desenvolvimento, seja pela falta de tradição na realização de inovações para além de um círculo muito restrito à produção de commodities.

A superação do paradigma desenvolvimentista, pautado na exploração insustentável dos recursos da biodiversidade, também é outro importante ponto a ser considerado como óbice para que os seres vivos possam ser mais bem utilizados, e não mais dentro de uma lógica norteada pela dilapidação dos recursos em busca de lucratividade imediata a todo custo, algo que não mais se enquadra dentro dos valores jurídicos da pós-modernidade, em que o bem ambiental adquire status de indisponibilidade, pois o desenvolvimento sustentável representa um valor jurídico ${ }^{5}$ para além das fronteiras tradicionais das nações, indo em direção aos interesses globais da humanidade para um ambiente equilibrado e capaz de atender não somente às gerações presentes, mas também às futuras.

Implica-se, nesse âmbito, a necessária compreensão de que a sustentabilidade representa, em verdade, um princípio jurídico de natureza estruturante, ${ }^{6}$ o que requer a consideração de determinados contornos principiológicos ${ }^{7}$ para permitir que tal valor jurídico possa ser bem aplicado, a fim de promover benefícios para a sociedade tanto no plano nacional quanto, principalmente, no internacional, cujos atores globais têm, nos últimos tempos, exigido o respeito desse valor jurídico, inclusive mediante estruturas de

Levando-se, aqui, em consideração que: "[...] A regulação administrativa é a intervenção indireta do Estado-administração, que visa a implementar, com autonomia, políticas constitucionalizadas (prioridades cogentes), via correção das falhas de mercado e de governo, em caráter promocional ou repressivo, de ordem a melhor tutelar a eficácia dos direitos fundamentais das gerações presentes e futuras" (FREITAS, 2015, p. 139) (grifos no original).

4 “XXIX - a lei assegurará aos autores de inventos industriais privilégio temporário para sua utilização, bem como proteção às criações industriais, à propriedade das marcas, aos nomes de empresas e a outros signos distintivos, tendo em vista o interesse social e o desenvolvimento tecnológico e econômico do País;" (BRASIL, 1988).

5 Como pode ser observado por meio da posição do constituinte originário brasileiro de 1988: "Art. 225. Todos têm direito ao meio ambiente ecologicamente equilibrado, bem de uso comum do povo e essencial à sadia qualidade de vida, impondo-se ao Poder Público e à coletividade o dever de defendê-lo e preservá-lo para as presentes e futuras gerações." (BRASIL, 1988).

CANOTILHO, 2010, p. 8.

Em especial: "[...] o princípio da sustentabilidade é um princípio aberto carecido de concretização conformadora e que não transporta soluções prontas, vivendo de ponderações e de decisões problemáticas. É possível, porém, recortar, desde logo, o imperativo categórico que está na génese do princípio da sustentabilidade e, se se preferir, da evolução sustentável: os humanos devem organizar os seus comportamentos e acções de forma a não viverem: (i) à custa da natureza; (ii) à custa de outros seres humanos; (iii) à custa de outras nações; (iiii) à custa de outras gerações. Em termos mais jurídico-políticos, dir-se-á que o princípio da sustentabilidade transporta três dimensões básicas: (1) a sustentabilidade interestatal, impondo a equidade entre países pobres e países ricos; (2) a sustentabilidade geracional que aponta para a equidade entre diferentes grupos etários da mesma geração (exemplo: jovem e velho); (3) a sustentabilidade intergeracional impositiva da equidade entre pessoas vivas no presente e pessoas que nascerão no futuro." (CANOTILHO, 2010, p. 8-9) (grifos no original). 
autorregulação. Sem, contudo, desprezar os meios mais tradicionais inseridos nos ordenamentos jurídicos para, de certo modo, atuar preventivamente, coibindo danos para a sociedade.

Tendo em vista que as estruturas jurídicas à disposição do Poder Público não podem jamais se furtar ao atendimento do imperativo mais basilar do interesse público, isto é, o de somente permitir a disponibilização no mercado de produtos e/ou processos biotecnológicos inovadores, que estejam numa esfera de biossegurança adequada para o bem comum, prevalece a indisponibilidade desse interesse público maior e que guarda relação com a sustentabilidade. Considerando-se também que:

\section{[...] quando a biotecnologia passa a ser fonte e a matriz de experiências que visam à criação original de linhagens de seres ou a modificação daquelas já existentes, é justificável que o ordenamento jurídico, expressando um justo receio da sociedade, procure limitar os efeitos que possam ser prejudiciais em virtude dessas práticas (SCAFF, 2012, p. 127).}

Em linha, vale frisar que as estruturas de autorregulação são ferramentas muito importantes para direcionar os caminhos do desenvolvimento sustentável para as atividades empresariais, não somente as biotecnológicas, mas também outras que, por seu impacto sobre os bens ambientais, exigem um olhar da sociedade para além de suas necessidades mais imediatas. Não se olvidando, porém, algumas particularidades encontradas numa sociedade altamente tecnológica, cujas inovações ocorrem numa velocidade maior do que a própria capacidade de modificações legislativas tradicionais, exigindo a atuação de outros atores do ecossistema das inovações biotecnológicas. Deve-se, também, levar em consideração que:

El sistema social se caracteriza por su complejidad. Sus protagonistas no son ya, como antaño, los individuos, con sus particulares intereses; el entramado social se articula hoy en torno a grupos profesionales, corporaciones, empresas, asociaciones, agrupaciones en suma, con una elevada capacidad de autorregulación. Las sociedades actuales se caracterizan también por ser sociedades amenazadas por el risco. Los daños que puede causar el desarrollo tecnológico no provienen de una aplicación de las nuevas tecnologías al margen de la legislación sino de riesgos intrínsecos, insospechados a veces, de la propia técnica. Tales riesgos no pueden ser eliminados por completo en ningún caso. Su adecuada gestión requiere al menos de la intervención de las organizaciones privadas que los generan, esto es, aquellas que poseen el dominio directo del desarrollo tecnológico y que son, a su vez, depositarias del conocimiento necesario para prever sus consecuencias (GARDELLA, 2002, p. 13).

Transformar um elemento da biodiversidade nativa de países em desenvolvimento em produtos e/ou processos biotecnológicos requer certa cautela, especialmente devido ao fato de que muitas dessas espécies são endêmicas, exigindo por parte do Estado uma atuação regulatória com padrões de respeitabilidade a princípios constitucionais importantíssimos para o interesse público da sadia qualidade de vida, nomeadamente princípios jurídicos do quilate do desenvolvimento sustentável e suas interfaces operacionais. Não esquecendo, contudo, a busca por outros valores relevantes para gerar progresso científico, tecnológico e inovativo para o país, preservando recursos estratégicos para as gerações presentes e futuras.

É possível, nessa óptica de valorização da biodiversidade para a geração de tecnologias úteis ao progresso da sociedade, invocar uma necessária vinculação dos inventos tutelados pelo direito patentário no desenvolvimento tecnológico e econômico ${ }^{8}$ com sustentabilidade, o que exigirá do Poder Público uma atuação regulatória suficiente e necessária para sempre exigir que tais direitos, considerados por parcela da doutrina como monopolistas, ${ }^{9}$ estejam adequados para atender ao imperativo da maior importância ao

8 Acerca desse princípio -de sede constitucional brasileira- , deve-se recordar que sua conformação jurídica poderá ser melhor compreendida quando o intérprete considerá-lo dentro da estrutura dinâmica do próprio sistema nacional científico e tecnológico, e da necessária interação com as universidades e institutos públicos de pesquisa, que muito podem contribuir com seus saberes basilares para inovar e até promover uma autonomia das biotecnologias nacionais (PEIXOTO NETO, 2013, p. 1196-1197).

9 Uma abordagem jurídica destes bens mais relacionada com uma vertente de direitos de monopólio, em detrimento a um foco mais direcionado com os direitos de propriedade, é defendida por importantes autores da contemporaneidade, no âmbito europeu, por exemplo Remo Franceschelli (1961), Casanova (1955), Guido Landi (1941) e Guglielmetti (1955) (ALMEIDA, 1999, p. 74-75). 
interesse público,$^{10}$ dado que as invenções relacionadas com a biodiversidade representam importantes mercadorias no complexo comércio internacional das biotecnologias, especialmente em áreas de vanguarda científica e tecnológica fortemente influenciadas por um processo predominantemente de mercantilização, de modo a considerar que:

A mercantilização geral do Direito Intelectual é um facto. Uma manifestação flagrante está na circunstância de a entidade que é hoje decisiva na disciplina dos direitos intelectuais não ser hoje, nem a UNESCO nem a OMPI, mas a Organização Mundial do Comércio-e isto quer no que respeita ao Direito de Autor e ao Direito de Informática, quer aos direitos industriais. São antes de mais objecto do comércio internacional (ASCENSÃO, 2002, p. 170).

Ocorre que muitas dessas inovações são empregadas para a melhoria da competitividade empresarial, criando, inclusive, barreiras de proteção à entrada de concorrência. Isto é reforçado por meio do emprego dos institutos da propriedade intelectual, ${ }^{11}$ que fornecem estruturas jurídicas, ou até camadas de tutela exclusiva intelectual, afastando concorrentes que não usaram recursos financeiros, humanos, logísticos e, até mesmo, de expertise empresarial para utilizarem essas criações de modo indevido e contrário ao direito de uma concorrência sadia. Tais firmas são um dos principais atores institucionais interessados na proteção desses estratégicos ativos da biodiversidade, seja oriunda do ambiente terrestre, seja, mais recentemente, advinda do ambiente marinho e costeiro, como uma nova fronteira de bioprospecção. ${ }^{12}$

Logo, as inovações biotecnológicas, bem como sua apropriação como uma espécie de ativo da biodiversidade para as empresas inovadoras, exigirão, por parte de países em desenvolvimento, ricos em biodiversidade, uma atenção maior da Administração Pública para fomentar tais criações intelectuais dentro de suas políticas públicas de modo sustentável, com direcionamento a um desenvolvimento econômico, social e tecnológico fundamentado no ideário maior da sustentabilidade.

\section{A autodeterminação ecológica em face das inovações biotecnológicas para a sustentabilidade}

As inovações biotecnológicas, por complexidade e interações ambientais, são potencialmente susceptíveis de gerar controvérsias significativas quanto à segurança ao meio ambiente, algo especialmente gravoso quando se adentra no campo da transgenia, quer dizer, da modificação de seres vivos por meio de técnicas de engenharia genética para atender a determinados objetivos científicos, tecnológicos e mercadológicos, o que exige a imperiosa aplicação das lentes da sustentabilidade, tendo em vista diversos aspectos que serão delineados a seguir, diante de certos interesses indispensáveis para a manutenção da qualidade de vida e para a preservação da própria biodiversidade.

10 Dado que o interesse público, aqui relativo aos direitos de propriedade intelectual, é complexo e exige uma atuação estatal sempre vigilante para evitar abusos, devendo-se, também, considerar que: "[...] o próprio regime jurídico dos direitos de propriedade intelectual procura, apesar de tudo, atingir um equilíbrio entre os interesses individuais dos titulares e os interesses públicos (bem como os interesses gerais) ligados, por exemplo, à promoção da inovação tecnológica (patente, modelo de utilidade, topografias de produtores semicondutores), à competitividade das empresas, à protecção das manifestações artísticas aplicadas aos objectos utilitários (desenhos e modelos e direito de autor), e à protecção das manifestações culturais stricto sensu (direito de autor)" (MARQUES, 2003, p. 322-323) (grifos no original).

11 Levando-se em consideração que: "[...] as interfaces entre a propriedade intelectual em biotecnologia com o direito, dá base para erigir todo um sistema significativamente complexo e de grande repercussão para o interesse público, aqui representado pela sua vertente de geração de riqueza, renda e desenvolvimento nacional em bases sustentáveis, agora diante do novíssimo instituto constitucional brasileiro expresso da inovação, repercutindo, por sua vez, em todo o sistema jurídico do Brasil, com a força de um valor constitucionalizado da mais elevada importância, por meio, especialmente, do fomento aos institutos jurídicos da patente e da proteção de cultivares dentro da relação universidade/empresa" (PEIXOTO NETO, 2016, p. 240).

12 A grande biodiversidade encontrada no ambiente marinho representa a nova fronteira para as empresas biotecnológicas, o que inegavelmente irá gerar controvérsias significativas, as quais exigirão o emprego das ferramentas jurídicas internacionalistas, tão bem expressas por meio da Convenção de Montego Bay de 1982, incluindo o emprego do próprio Tribunal Internacional do Direito do Mar. Considerando-se que para países como o Brasil, com uma área litorânea vastíssima, sua utilização de modo sustentável poderá ser muito importante para o desenvolvimento econômico, social e até tecnológico nacional. Tudo isto diante do fato de que: "Não é difícil intuir, a partir dos interesses associados a recursos naturais que estão inseridos em dois terços da superfície terrestre, a importância do adequado trato de questões que perpassam, em muito, a esfera das relações entre os países. A multiplicidade de questões vinculadas a uma distribuição mais justa e a uma exploração mais racional dos recursos naturais, tem importância não apenas para o desenvolvimento dos países que não compõem a lista das superpotências mundiais, mas também para a própria sobrevivência da humanidade, o que faz com que se preveja para o regime oceânico internacional o status de um verdadeiro pilar da ordem internacional que se vai estabelecer no século que se inicia" (MICHELS, 2004, p. 112). 
Os debates acerca dos transgênicos, referentes à sua segurança e aos impactos sobre o meio ambiente, são relativamente recentes, cerca de pouco mais de duas décadas e meia, o que faz com que inúmeros pesquisadores debrucem-se sobre essa temática, principalmente com foco nas interfaces da ciência e da política na matéria, tendo em vista, também, que a opinião formada acaba por apresentar uma força significativa, por vezes até igual à força científica tradicional comprovada (GRAY, 2014, p. 923), o que gera novos desafios, principalmente num cenário que emprega conceitos complexos e difíceis, como o da sustentabilidade e o da biodiversidade, por vezes utilizados nessa seara (GRAY, 2014, p. 930).

Tal questão leva o direito a participar desse debate, com suas ferramentas e lentes sobre a realidade da sociedade e suas repercussões no seu campo de atuação, como uma ciência social aplicada de regulação de condutas e dos fatos de interesses econômicos, sociais, políticos e ambientais, a que é chamado por seu papel e autonomia, ${ }^{13}$ fazendo com que possa levar em consideração tradicionais valores jurídicos para analisar a problemática de novas tecnologias, como o valor jurídico da autodeterminação.

A autodeterminação é um princípio do direito internacional consagrado na Carta das Nações Unidas de $1945^{14}$, que, logo no seu n. ${ }^{\circ} 2^{\circ}$, artigo $1^{\circ}$, põe esse valor jurídico numa posição de elevada consideração. Visa assegurar aos povos a capacidade de poderem escolher o rumo mais adequado dentro de sua formação cultural, histórica e política sem sofrerem graves interferências nesse caminho natural da busca por uma identidade própria e de autoafirmação perante a comunidade internacional, e tem desempenhado papel importante em outros instrumentos de direito internacional da Organização das Nações Unidas (ONU), com destaque para a Declaração sobre a Concessão de Independência aos Países e Povos Coloniais de 1960, que fez referência àquele como um direito no Pacto Internacional sobre Direitos Humanos de 1966, e foi utilizado como instrumento para combater o apartheid na África do Sul (ANJOS FILHO, 2013, p. 588-590).

Do princípio supracitado, contudo, podem irradiar outros valores que, com a evolução das relações sociais, novas conquistas e formas de enxergar o outro, dentro de suas peculiaridades como povo-detentor de visões sobre a realidade distinta de outros povos -, pode seguir os rumos que entender mais adequados, dentro de um arcabouço minimamente aceitável e devidamente assentado nos direitos humanos. Isto leva à possibilidade da construção de uma possível ramificação do clássico princípio da autodeterminação para uma vertente ecológica. Assim, adentra-se num campo mais específico de uma autodeterminação ecológica para as inovações biotecnológicas.

Como decorre mesmo da autodeterminação e, em sua essência, tem a autodeterminação ecológica, por premissa, o respeito à escolha dos rumos mais adequados que cada povo deverá optar ou não do ponto de vista ambiental e tecnológico, pela aceitação ou não de determinadas formas de ver a natureza e de inter-relacionar-se com ela de modo harmônico - sem ter que ser obrigado a internalizar determinadas criações intelectuais que considera inadequadas a essa harmonia -, o que não quer dizer que, em determinadas matérias, já bem consolidadas do ponto de vista científico, não se busque a incorporação dessas biotecnologias. ${ }^{15}$

13 Acerca da problemática da autonomia do direito, deve-se considerar que é tema complexo e que exige um olhar atento para suas repercussões quanto à própria capacidade de um diálogo promissor com outros campos das ciências, que inegavelmente são exigíveis quando se encontram em tela interesses públicos importantíssimos para o bem da coletividade, verificáveis nas inovações biotecnológicas. De modo que se deve, então, atentar e refletir sobre o seguinte cunho jusfilosófico: “(...) ao falar de «autonomia» (autonomia do direito) pretendo naturalmente referir-me a uma sua autossuficiência de sentido e não menos à sua autoafirmada especificidade já intencional nos fundamentos, já teleológica nos critérios, já de material determinação nos conteúdos - sem excluir decerto a possível, a necessária integração no global universo prático-humano: se o direito for aí autónomo, no seu sentido e na sua manifestação, nem por isso deixará de ser obviamente elemento desse universo." (CASTANHEIRA NEVES, 2012, p. 21).

14 Esse importante instrumento jurídico internacional foi devidamente internalizado por diversos países, como o Brasil, por meio do Decreto $\mathrm{n}^{\circ}$. 19.841, de 22 de outubro de 1945

15 Dentre essas tecnologias, os transgênicos apresentam questões ainda não totalmente esclarecidas, mas não se pode desconsiderar, também, seus possíveis benefícios. Daí, ao analisar os riscos e vantagens que podem advir de tais tecnologias, tem-se em tela que somente o tempo e uma apurada comparação imparcial entre outros métodos agrícolas de produção, será possível, caso a caso, elucidar os riscos e benefícios da adoção destas biotecnologias, face a outras já consolidadas. Neste sentido, ao analisar os pontos positivos e negativos da utilização dos transgênicos na agricultura, uma série de fatores deverão ser ponderados diante das possibilidades de produção disponíveis, com destaque para a comparação com práticas agrícolas como a agricultura biológica e a convencional, o que poderá, em decorrência ainda de certa imprecisão e de limitações em prever todos os impactos ecológicos de longo prazo das espécies modificadas introduzidas no ambiente, ser exigido um repensar da própria gestão dos riscos (WOLFENBARGER; PHIFER, 2000, p. 2092). 
A título exemplificativo pode ser citada uma prática agrícola consagrada em muitas culturas: as queimadas ${ }^{16}$. Estas são utilizadas para a renovação de áreas agrícolas, prática que ocasiona enormes impactos ambientais, e até na produção agrícola, cujos danos não conhecem fronteiras, devido ao aumento dos gases do efeito estufa, que também ameaçam a sadia qualidade de vida. Não é isso o que se quer defender com a possibilidade de aplicação da autodeterminação ecológica, mas que, em caso de conflito claro entre o emprego de nova biotecnologia agrícola, ainda repleta de incertezas científicas, que possam ameaçar a coexistência de modos de vida ecologicamente aceitáveis, determinados povos façam suas escolhas de aceitação ou repulsa daquela tecnologia, dentro dos limites ou nas cercanias de suas áreas tradicionais de cultivo.

Nessa direção, uma autodeterminação ecológica para inovações biotecnológicas passará, necessariamente, pelo princípio do desenvolvimento sustentável, tão bem delineado na Declaração do Rio de Janeiro sobre Meio Ambiente e Desenvolvimento de 1992 (Rio-92), que trouxe esse valor de modo expresso para o sistema jurídico internacional ambiental como norte a ser perseguido na busca das escolhas dos países, as quais devem ser pautadas por esse valor jurídico indispensável para o equilíbrio entre a necessidade da sobrevivência humana digna e harmônica com a natureza e a própria soberania que os Estados devem ter sobre seus recursos naturais, sendo tudo isto pautado sempre pelo interesse das gerações presentes e futuras, não sendo mais aceitável uma dissociação entre o desenvolvimento e a necessidade de um meio ambiente equilibrado. ${ }^{17}$

A busca pela compreensão das diferenças intrínsecas para a autodeterminação ecológica de produtos e/ou processos biotecnológicos é algo em contínua construção. E, diante da complexidade das sociedades pós-modernas e das mudanças nas tecnologias, é algo especialíssimo quando se trata da questão de transgênicos na agricultura face às aversões que existem, advindas, em parte, das dúvidas científicas que ainda pairam sobre a questão, e também devido às resistências que poderão resultar do receio de determinadas populações quanto à possibilidade de perda da biodiversidade das variedades domésticas tradicionais, o que poderá acarretar uma maior dependência de comunidades pelos denominados pacotes tecnológicos agrícolas, ${ }^{18}$ que são capazes de gerar forte vinculação econômica para os grandes grupos econômicos deste setor.

Tal consideração perpassa o fato de que a autodeterminação, como representante de um direito que assiste os povos na busca por caminhos que acreditam ser os mais corretos, não poderá, contudo, ser aplicada de modo exclusivo, mas devidamente compreendida dentro de um sistema dinâmico e sujeita a ponderações que devem seguir critérios que levem em consideração uma conjuntura econômica, social e política, tendo em vista a complexidade em que as opções ecológicas estão assentadas e as repercussões locais, regionais e até globais que podem estar envoltas nestas. Essa problemática acaba por atingir a necessidade de uma visão transdisciplinar da realidade, tendo em tela a forte influência das formas pelas

16 A realização das queimadas é muito antiga. Em diversas regiões do mundo é utilizada como prática agrícola, sujeita a enormes debates para sua eliminação. Um dos exemplos de grande relevo, em decorrência da escala com que é empregada, refere-se à cana-de-açúcar que, no Brasil, tem sido objeto de diversas legislações no sentido de ser abolida, apesar de encontrar dificuldades em decorrência da necessidade de geração de empregos para certos estrados populacionais, o que é nitidamente verificado por meio da Lei do Estado de São Paulo, sob o n. ${ }^{\circ} 11.241$, de 19 de setembro de 2002, que trata da eliminação gradual dessa prática nos canaviais paulistas.

17 Essas considerações podem ser depreendidas dos princípios 1 a 4 da Declaração da Rio-92: "Princípio 1. Os seres humanos estão no centro das preocupações com o desenvolvimento sustentável. Têm direito a uma vida saudável e produtiva, em harmonia com a natureza. Princípio 2 . Os Estados, de acordo com a Carta das Nações Unidas e com os princípios do direito internacional, têm o direito soberano de explorar seus próprios recursos segundo suas próprias políticas de meio ambiente e de desenvolvimento, e a responsabilidade de assegurar que atividades sob sua jurisdição ou seu controle não causem danos ao meio ambiente de outros Estados ou de áreas além dos limites da jurisdição nacional. Princípio 3. O direito ao desenvolvimento deve ser exercido de modo a permitir que sejam atendidas equitativamente as necessidades de desenvolvimento e de meio ambiente das gerações presentes e futuras. Princípio 4. Para alcançar o desenvolvimento sustentável, a proteção ambiental constituirá parte integrante do processo de desenvolvimento e não pode ser considerada isoladamente deste.".

18 Considerando que: "[...] no caso brasileiro pode-se verificar uma particularidade que integra uma estratégia de negócio das grandes empresas biotecnológicas agrícolas, qual seja: a vinculação da proteção intelectual a uma espécie de pacote tecnológico, onde para se obter uma produtividade aceitável, dentro do modelo capitalista, o produtor rural deverá aderir quase que obrigatoriamente a todo um modelo de tecnologias que integram o portfólio da empresa biotecnológica." (PEIXOTO NETO, 2014, p. 136). 
quais a racionalidade humana tem sido calcada nos últimos tempos, levando-se em consideração os próprios limites científicos, dentro de suas esferas de atuação. ${ }^{19}$

A conformação dos transgênicos no plano ambiental deverá passar por uma visão devidamente integrada no plano socioambiental, pois ainda será visto como essas inovações biotecnológicas serão aceitas por parcela da sociedade, diante de certas dúvidas que ainda surgem sobre aqueles, com a devida valoração. Isto levará a um olhar diferenciado quanto aos riscos e/ou aos benefícios que tais invenções podem trazer para as diversas sociedades, que irão se alimentar deles, e não se pode olvidar, também, as questões de cunho cultural, pois as visões de mundo podem ser totalmente contrárias ao emprego de tais recursos alimentares.

Com isso, deverá ser levada em consideração a necessidade de que os valores ambientais maiores - a sadia qualidade de vida e a preservação da biodiversidade, entre outros -, diante das incertezas quanto à segurança, sejam alvo de um juízo devidamente conformado com um adequado processo de ponderar e hierarquizar, mesmo para as denominadas de "prioridades ambientais", por meio do emprego de critérios pertinentes à questão, cujas esferas a serem consideradas são: a científica, a social e a política (ARAGÃO, 2014, p. 244).

Ao analisar esses critérios, os de natureza científica podem contribuir para trazer luz a certos pontos, em especial quando se tratar da proteção de determinados seres vivos que podem ter um papel de relevo para um determinado ecossistema, mas por não deterem características que possam despertar "compaixão"20 podem correr sério risco de extinção e até, quiçá, comprometerem outros organismos vivos que dependam da atividade realizada por aqueles (ARAGÃO, 2014, p. 244).

O respeito ao modo de vida de determinadas comunidades e povos é premissa fundamental para uma sociedade plural e que adota padrões ético-jurídicos coerentes com as grandes conquistas no plano internacional dos direitos humanos. Isto implica olhar sob as lentes da alteridade ${ }^{21}$ compreendendo suas diferenças e com respeito ao seu modo de vida, o que envolve um atuar do Estado no sentido de assegurar o direito de coexistência de seu modo de vida ecológico, exigindo, no caso dos transgênicos, a adoção de ressalvas para evitar a contaminação das variedades tradicionais dessas populações.

Deve-se considerar o que traz a Convenção n. ${ }^{\circ} 169^{22}$ da Organização Internacional do Trabalho (OIT), a qual, ao tratar dos povos indígenas e tribais, considera, no seu artigo $8^{\circ}$, que os Estados, ao aplicarem uma legislação de cunho nacional a essas populações, deverão observar seus costumes e mesmo seu direito costumeiro, ressaltando as questões ligadas às incompatibilidades com os direitos humanos. Este instrumento internacional demonstra a preocupação de que os estados nacionais valorizem, de maneira adequada, o modo de viver daquelas comunidades tradicionais. Isto implica em outro aspecto a ser considerado no processo de conformação das autorizações dos transgênicos: as áreas utilizadas, as quais podem colocar em risco as variedades tradicionais de povos, muitas destas imprescindíveis para a preservação de seu modo de vida.

19 A este respeito vale trazer à baila que: "A ciência moderna legitima as referências da produção em massa, do consumo além do limite das necessidades, do individualismo, da competição que aniquila, da produção ideológica do outro, de variados outros, e de exterioridades e inferioridades. Carrega as suas umas aspas, a ciência, porque, moderna, se revela como uma palavra coberta de poder que coloniza saberes e o próprio ser [...]" (HISSA, 2008, p.18) (grifos no original).

20 A título de exemplo pode ser citada a flor do maracujazeiro, cuja polinização é muito dependente de um inseto conhecido como mamangaba (Xylocopa sp.), um inseto meio desajeitado e que as pessoas não dão muita importância, mas essencial para essa frutífera no Brasil, tendo sido observado que o percentual de vingamento dos frutos dependerá da quantidade desses insetos no ambiente (JUNQUEIRA et al., 2001, p. 9-10).

21 A alteridade permite enxergar o outro com as suas diferenças e respeitá-las, o que pode ser bem elucidado pelo fato de que: "A temática, no entanto, sempre esteve presente nas reflexões da antropologia. Para essa ciência, a alteridade se constitui, desde a sua emergência, em desafio a ser explicado, posto que a antropologia se estrutura sobre a temática cultura. Nesse sentido, tem prestado relevantes contribuições na medida em que suas investigações tratam de mostrar o outro como diferença, desvendando suas características e especificidades." (ZANELLA, 2005, p. 100).

22 "Artigo $8^{\circ}$ I. Ao aplicar a legislação nacional aos povos interessados deverão ser levados na devida consideração seus costumes ou seu direito consuetudinário. 2. Esses povos deverão ter o direito de conservar seus costumes e instituições próprias, desde que eles não sejam incompatíveis com os direitos fundamentais definidos pelo sistema jurídico nacional nem com os direitos humanos internacionalmente reconhecidos. Sempre que for necessário, deverão ser estabelecidos procedimentos para se solucionar os conflitos que possam surgir na aplicação deste principio. 3 . A aplicação dos parágrafos I e 2 deste Artigo não deverá impedir que os membros desses povos exerçam os direitos reconhecidos para todos os cidadãos do país e assumam as obrigações correspondentes" (Convenção 169 da OIT). 
Dessa feita, é possível levantar mais um ponto a favor de uma autodeterminação ecológica dos povos no campo das inovações biotecnológicas: o das comunidades indígenas e tribais, que têm um modo de vida por vezes muito dependente de determinadas culturas vegetais, e que podem sofrer ameaça de extinção em caso de não atendimento de critérios adequados de biossegurança nas cercanias de suas áreas tradicionais de cultivo e/ou coleta de material para a manutenção de seu modo de vida tradicional, cabendo ao Estado buscar meios para tutelar tais bens coletivos.

Também há de se considerar que a opção por uma agricultura agroecológica com suas tecnologias seja mais aceita do que quando se adotam os transgênicos, que, em geral, são oriundos de empresas transnacionais e que acabam por entrar em choque com interesses de determinados estrados sociais, sendo essa forma de agricultura, fundada nos organismos modificados geneticamente, detentora de maior dificuldade para uma coexistência pacífica com outras formas de produção, o que exige medidas preventivas para evitar a contaminação das variedades tradicionais (MARICONDA; RAMOS, 2003, p. 259).

Outrossim, deverá ser observado que os aspectos relativos à aceitabilidade ${ }^{23}$ ou não da utilização de organismos vivos geneticamente modificados poderá sofrer forte influência das crenças e valores de certa sociedade, em especial das sociedades mais tradicionais, que buscam com muito esforço conservar seus valores culturais e saberes, remetendo a uma alteridade imprescindível para uma convivência mais harmoniosa entre valores culturais distintos, que podem influir nas escolhas de cada povo quanto às tecnologias agrícolas que desejam ou não utilizar.

Tais questões ainda representam um grande desafio para uma parcela da sociedade pós-moderna que nem sempre consegue enxergar o outro através de lentes isentas de preconceitos, também desprovida de um fundamento ético-jurídico aceitável. Isto leva à compreensão de que: "Cultura é a principal fonte de distinção dos povos para a antropologia, porém ela não estabelece nenhum grau de hierarquia entre as culturas. As características de uma ou outra são próprias do povo que as pratica, não devendo consistir em um fator de discriminação" (WANDSCHEER, 2009, p. 86).

A participação das populações interessadas deverá ser levada em conta para a adoção ou não de determinadas biotecnologias, algo muito importante, pois tem íntima relação com a autodeterminação ambiental, que pode ser relacionada com o próprio modo de vida, especialmente por questões éticas e religiosas que jamais podem ser desconsideradas no seio de uma sociedade minimamente detentora de padrões de respeito aos direitos humanos. A esse respeito, no âmbito da União Europeia, a Directiva 2001/18/CE no considerando (9) assim dispõe:

(9) O respeito pelos princípios éticos reconhecidos num Estado-Membro reveste-se de especial importância. Os Estados-Membros poderão tomar em consideração aspectos éticos quando sejam deliberadamente libertados ou colocados no mercado produtos que contenham ou sejam constituídos por OGM (Directiva 2001/18/CE).

Isto exigirá uma adequada avaliação estratégica, que poderá ser complementada com a possibilidade da realização de um referendo como forma de melhor legitimação, diante da autodeterminação ecológica, apesar de que, recentemente, o Governo brasileiro editou o Decreto n. ${ }^{\circ} 8.284$, de 21 de junho de 2014, que permite uma maior participação dos movimentos sociais na gestão pública por meio da criação da denominada Política Nacional de Participação Social (PNPS).

\footnotetext{
Como iniciativa importante para avaliação da aceitabilidade das pessoas, acerca de determinados temas que geram polêmicas e que repercutem na vida de milhões de indivíduos, tem-se o Eurobarómetro, que possui por objetivo a realização de pesquisas junto aos cidadãos dos Estados Membros da União Europeia e que, no âmbito dos transgênicos, constatou que apenas $27 \%$ concordariam totalmente ou estariam dispostos aos organismos geneticamente modificados nos alimentos, contrastando com $57 \%$ que não aceitariam suportar esses alimentos modificados geneticamente. Isto demonstra uma repulsa da maioria no âmbito da União Europeia, quanto à utilização dos transgênicos para os alimentos, variando conforme o país e também ao longo do tempo, o que comprova visões de mundo distintas e até o nível de conhecimento que vem sendo desenvolvido e divulgado perante essas populações. A título exemplificativo vale frisar os dois extremos: aqueles que concordam ou concordam totalmente que esse tipo de alimento deveria ser encorajado - Finlândia (1996 - 65\% e 2010- 30\%), Espanha (1996 - 66\% e 2010- 35\%), Portugal (1996 - 63\% e 2010- 37\%), Holanda (1996 - 59\% e 2010-30\%), Bélgica (1996 - 57\% e 2010- 28\%) e os contrários - a Áustria (1996 - 22\% e $2010-$ 23\%), Grécia (1996 - 49\% e 2010- 10\%), França (1996 - 43\% e 2010- 16\%), Luxemburgo (1996 - 44\% e 2010 - 19\%) e Alemanha (1996 - 47\% e 2010- 22\%) (UNIÃO EUROPEIA, 2010, p. 14, 50).
} 
O problema é que, em determinados países, como o Brasil, a participação popular direta nas decisões é pouca, sendo muito pequeno o número de referendos e plebiscitos que foram realizados no país desde o início da Constituição Brasileira de 1988, persistindo a ausência de uma amplitude que já é adotada em países membros da União Europeia, como Portugal, que em sua Constituição, por meio do artigo $115^{\circ},{ }^{24}$ permite um maior leque de possibilidades para o emprego de referendo, importante instrumento democrático vinculativo, para que os cidadãos possam ter o direito de fazer suas escolhas com maior legitimidade democrática.

Outro ponto que merece destaque diante da procura por uma autodeterminação ecológica e da questão dos transgênicos refere-se ao fato de que, como já ocorre na defesa do modo de vida de populações tradicionais e dos povos indígenas-que têm uma visão de mundo, por vezes, avessa ao modelo moderno ocidental, conservando suas crenças e valores como uma das expressões da valorização das diferenças e do respeito à dignidade da pessoa humana de cada membro -, aceitar a recusa de um determinado país em manter seu território isento de plantas transgênicas, no plano da busca por uma realização do direito, é respeitar o "diferente" valorizando a pessoa humana. ${ }^{25}$

Nessa direção, o Protocolo de Kiev pode desempenhar um papel importante, pois, ao se analisar a questão da participação pública, tal protocolo, no artigo $8^{\circ}$, de 1 a 4 , busca assegurar meios para que as populações participem das avaliações estratégicas, ainda garantindo que as organizações não governamentais possam expressar sua opinião sobre os relatórios ambientais (UNITED NATIONS, 2003, p. 5).

Com isso, segundo o Manual de aplicações práticas desse protocolo, publicado pelas Nações Unidas em 2012, defende-se que a garantia de participação do público refere-se não a qualquer público, mas àquele de natureza qualificada, que contribuirá para a construção de uma estratégia mais adequada e que poderá integrar o programa de relatório ambiental, em que o público geral terá direito à informação (UNITED NATIONS, 2012, p. 13).

Além disso, seguindo uma interpretação conjunta com a Convenção de Aarhus, pode-se considerar que o público afetado pelas medidas deverá ter o direito a essa participação durante o processo de tomada de decisão ambiental. Além disso, que devem ser adotadas medidas publicitárias para que, de modo adequado, seja garantido um bom acesso a informações, o que pode incluir a mídia eletrônica e materiais impressos, entre outros (UNITED NATIONS, 2012, p. 13-14).

Da mesma forma não se deve deixar de levantar a bandeira das questões atinentes à bioética, a qual é objeto de valoração nos planos europeu e estadunidense e que vai além dos tradicionais debates quase que exclusivamente econômicos, sem desmerecer esse valor que, numa óptica mais alargada de uma sociedade globalizada e do conhecimento, para além da visão reducionista sobre os transgênicos e da própria possibilidade de concessão de direitos inerentes à propriedade imaterial, não deverá deixar de ser considerado. ${ }^{26}$

Nessa linha, a título exemplificativo, vale citar o papel da Comissão Técnica de Biossegurança (CTNBio) no Brasil, criada por meio da Lei $n^{\circ}$. 11.105, de 24 de março de 2005, que apresenta em sua composição diversos membros da academia e da sociedade civil para analisar a viabilidade da liberação

24 Como se lê no artigo $115 .^{\circ}$ da Constituição da República Portuguesa de 1976: “ 1. Os cidadãos eleitores recenseados no território nacional podem ser chamados a pronunciar-se directamente, a título vinculativo, através de referendo, por decisão do Presidente da República, mediante proposta da Assembleia da República ou do Governo, em matérias das respectivas competências, nos casos e nos termos previstos na Constituição e na lei." (CRP/1976).

25 Nunca será demais lembrar que: "o reconhecimento da sociodiversidade e da biodiversidade é essencial para a implementação de mecanismos que possam garantir a existência do Outro. O caminho para uma sociedade mais justa e fraterna depende da aceitação do diferente sem preconceito e sem a imposição de padrões culturais com o objetivo de homogeneizar a humanidade com a imposição de padrões" (WANDSCHEER, 2009, p. 169).

26 Deve-se atentar para o fato de que, no plano da propriedade de bens de natureza intelectual, especialmente quando se engloba a viabilidade de uma apropriação privada de seres vivos - que foram objeto de intervenção criativa do homem-, também outras visões de mundo relacionadas ao próprio viver em sociedade devem ser consideradas, integrando a base do bem viver dentro de padrões éticos e de moralidade. 
desses organismos, totalizando 27 componentes (artigo 11, da Lei $n^{\circ} .11 .105 / 2005$ ), que deverão ser pessoas de notório conhecimento científico e competência técnica para decidir sobre essas questões. ${ }^{27}$

Essa estrutura de liberação dos transgênicos poderá ser beneficiada por meio da realização de auditoria ambiental, tendo em vista que essa ferramenta pode contribuir para uma avaliação continuada, diante da busca por uma maior compatibilização entre os interesses empresariais dos produtores e os dos detentores dos direitos da propriedade imaterial dos transgênicos, considerando o interesse público de um ambiente ecologicamente equilibrado ${ }^{28}$ e um desenvolvimento sustentável.

Também a racionalidade dessas questões não poderá ser exclusivamente econômica, mas pautada em valores jurídico-ambientais que perpassam por uma criteriosa avaliação entre os riscos envolvidos e os benefícios que serão trazidos para a sociedade. Tal equacionamento levará à discussão sobre o respeito à função social da empresa, que, por mais que tenha como foco o lucro para seus sócios, não mais se admite que possa estar alheia aos seus compromissos com a sociedade que a sustenta, por meio da aquisição de boa-fé dos seus produtos.

Essa busca não é fácil, pois seria no mínimo ingênuo acreditar que somente os olhos do mercado poderiam ser suficientes para controlar setores em cujas empresas, por vezes, têm um lucro anual superior ao Produto Interno Bruto (PIB) da maioria dos países onde atuam, o que gera a necessidade dos Estados de utilizarem os meios regulatórios adequados e suficientes para fomentar condutas acertadas com os interesses públicos, aqui representados pelo meio ambiente equilibrado, pois a concessão dos exclusivos de seres vivos pode, se não forem bem regulados, vir a causar o surgimento de monopólios muito fortes, que podem levar a uma concentração excessiva de poder econômico.

Nessa linha, há de ser lembrado que a concentração de poder econômico poderá ser um perigo, pois, "por encima de cualquier ventaja técnica que pueda apreciarse en tal situación, la concentración económica es siempre un mal grave, desde el punto de vista de los objetivos polítics y sociales del Estado y del interés público" (CORROZA, 1993, p. 282), levando à constatação de que:

[...] la competencia monopolística fuerza al derecho a estabelecer una regulación de la actividad concurrencial, y hace necesaria una fuerte disciplina de la competencia, para evitar su desnaturalización, a través prácticas restrictivas, su mixtificación mediante maniobras desleales y su desaparición por medio de procesos de concentración de poder económico en manos privados, capaces de crear la peor de las opresiones, que es la económica (CORROZA, 1993, p. 282).

Assim, não se poderá negar, ainda, que a autodeterminação ecológica dos povos cria uma obrigatoriedade no sentido de que as populações locais possam ser ouvidas, principalmente diante da conformação jurídicoambiental dos transgênicos, os quais apresentam contornos bastante sensíveis para a sadia qualidade de vida e para a preservação do bem ambiental para as gerações presentes e futuras, levando à necessidade

27 Apesar da Lei n. ${ }^{0} 11.105 / 2005$ prever no seu artigo 11 que, para a composição dos membros, estes deverão ter um saber reconhecido na área, restringindo tal saber à biossegurança, à biotecnologia, à biologia, à saúde humana e animal ou meio ambiente. Deverá ter, também, profissionais de outros campos do saber, a fim de que possa se considerar mais aspectos relevantes acerca das autorizações, principalmente no tocante a questões sociais, visto que, segundo o $\S 8^{\circ}$ desse diploma legal, a decisão é feita por maioria absoluta dos seus membros e não por unanimidade, o que é muito salutar, tendo em vista as incertezas que ainda pairam nos campos biotecnológicos, cujas lentes científicas multidisciplinares enriquecem o debate decisório, legitimando-o. Nesta direção, em decorrência dos esforços da esfera ambiental do Governo brasileiro, foram introduzidas em um dispositivo, através do Decreto $n^{\circ} 5.591$, de 23 de março de 2005, as hipóteses de liberação mediante dois terços dos membros favoráveis, mas esta realidade mudou pela alteração legislativa da Lei n. ${ }^{\circ} 11.460$, de 21 de março de 2007 , que estipulou como critério a maioria absoluta. (DIAS, 2009, p. 29)

28 A adequação das necessidades de natureza econômica, para o estímulo do desenvolvimento de novas plantas transgênicas, deve seguir na direção da elaboração de políticas públicas que possam ser capazes de adequar estas biotecnologias dentro da esfera da indisponibilidade do bem ambiental sadio, algo nem sempre fácil de ser realizado, diante das consideráveis pressões dos diversos atores econômicos, os quais integram as bases produtivas do agronegócio e as grandes empresas desenvolvedoras destas tecnologias de alto valor agregado. Isto exige um contínuo processo de reavaliação das tecnologias que ainda apresentam certo grau de incerteza capaz de causar danos a esse bem indisponível ao desenvolvimento em fundamentos sustentáveis. A importância dessa ferramenta de origem estadunidense, na década de 1960, e cujo contexto surge em decorrência da complexidade jurídico-ambiental legislativa, contribui no processo de organização, gerenciamento e atenção à exigibilidade da legislação ambiental, isto implica que este pode se tornar um instrumento viável de compatibilização entre a atividade econômica e as necessidades ambientais, o que contribui para a construção de uma "empresa ecologicamente equilibrada" (FREITAS, 2013, p. 297-305). 
da realização de uma proporcionalidade delimitada por balizas, ora da prevenção ${ }^{29}$ ora da precaução, ${ }^{30}$ para que seja alcançado um emprego racional dessas biotecnologias genéticas na direção de um desenvolvimento pautado na sustentabilidade.

\section{Conclusão}

As inovações biotecnológicas despertam grandes dúvidas no seio social, com repercussões nos diversos campos do saber. O que não é diferente para o direito, que, como instrumento de pacificação das relações humanas, deve responder à altura com seus instrumentos de regulação e controle das situações, mantendo uma interpretação jurídica sempre condizente com os valores democráticos de uma sociedade plural, globalizada e do risco.

As novas biotecnologias provocam polêmicas e debates acirrados, logo para lidar com outras ciências tais inovações precisam realizar um diálogo que leve em conta valores juridicamente relevantes, a exemplo do desenvolvimento tecnológico e econômico, com foco na sustentabilidade.

Tais inovações tecnológicas da biodiversidade precisam estar preparadas para utilizarem suas ferramentas e lentes de compreensão para uma realidade que poderá exigir, em homenagem à tutela do bem ambiental, uma visão não somente em curto prazo, mas também em médio e longo prazo, atendendo as diversas demandas exigidas pela sociedade.

Logo, diante de problemas complexos, as soluções do direito não podem desprezar o desejo e as necessidades de cada povo na determinação dos melhores rumos que desejam seguir, quanto ao uso de determinadas tecnologias, cujas repercussões para as gerações futuras ainda se sujeitam ao imperativo jurídico da precaução e/ou da prevenção, como recursos valiosos para o uso racional e sustentável da biodiversidade.

Diante disso, outras ferramentas jurídicas podem ser adotadas para permitir uma conformação mais adequada dessas tecnologias inovadoras, como a da autodeterminação_conquistada a duras penas e que adquire determinadas vertentes -, e que pode contribuir para uma maior sustentabilidade para as gerações presentes e futuras, na direção da conservação da diversidade biológica e também cultural de cada povo, que deverá ter o direito de ditar seus rumos biotecnológicos adequados. Isto não significa que, no plano internacional, possam ser adotadas medidas em áreas transfronteiriças sensíveis ao impacto dessas novas tecnologias; exigindo-se, nesses casos, o emprego dos tribunais internacionais, por vezes, para a solução de controvérsias dessa magnitude, já que os impactos ambientais ultrapassarão os limites das fronteiras tradicionais.

Deve-se considerar que a aplicação da autodeterminação ecológica dos povos não significa um obstáculo ao desenvolvimento científico e tecnológico, mas simplesmente uma nova forma de garantir que cada povo possa optar pelo emprego de determinadas biotecnologias, as quais se encontram, ainda, num campo de incertezas científicas, cujas repercussões podem ultrapassar a presente geração e até vir a comprometer recursos naturais finitos e de difícil reparação. Daí a necessidade dos juristas modernos utilizarem com destreza as lentes do princípio do desenvolvimento sustentável com valores tradicionais internacionalistas, como o da autodeterminação dos povos.

29 Tal princípio jurídico desempenha um papel muito importante na promoção da sustentabilidade para o bem ambiental, motivo pelo qual sua adequada aplicação no campo das inovações biotecnológicas sempre será bastante valiosa para assegurar uma sadia qualidade de vida para a sociedade. Assim, não se olvida que o princípio da prevenção pode ser encontrado nos próprios alicerces do Direito ambiental, permitindo a identificação de toda uma cadeia de causalidade, disciplinando a própria ação humana, de modo a considerar: "sempre com base em uma correlativa certeza científica" - "[...] siempre con base en una correlativa certeza científica” (MOREIRA NETO, 2011, p. 484) (tradução livre).

30 Como um instrumento jurídico indispensável para a proteção do meio ambiente, principalmente em matéria de organismos geneticamente modificados, em especial por sua forte natureza cautelar de proteção ao meio ambiente. Assim, há de ser levado em conta que: "[...] o princípio da precaução é imperativo constitucional, que materializa a tutela cautelar do meio ambiente, mediante indispensável estudo prévio de impacto ambiental, a ser realizado por competente e imparcial equipe multidisciplinar, para o plantio e a comercialização da soja transgênica (round up ready) bem assim para a liberação de qualquer organismo geneticamente modificado, nas vertentes do meio ambiente, como garantia fundamental das presentes e futuras gerações" (PRUDENTE, 2004, p.79) (grifos no original). 
A autodeterminação ecológica no âmbito das inovações biotecnológicas representa um direito que os povos têm para dizer como preferem utilizar essas criações humanas ou mesmo decidir por sua não adoção no seu território, cujas escolhas político-jurídicas podem ser pautadas por graus diferentes de tolerância ao próprio risco biotecnológico do desenvolvimento suportado por cada povo, dentro de seus valores culturais, e até para o campo de suas conviç̧ões religiosas.

A aceitação ou repulsão de uma dada inovação, sujeita a determinados riscos e fundada na autodeterminação ecológica de uma nação, repercutirá em importantes esferas relacionadas ao próprio valor jurídico do desenvolvimento tecnológico, econômico e socioambiental, dentro de parâmetros de sustentabilidade que podem repercutir para além do seu território já na geração presente. Isto implica dizer que a invocação desse tipo de autodeterminação adentrará no campo da propriedade intelectual em biotecnologia, com seus institutos típicos de apropriação exclusiva dessas tecnologias - apesar das restrições impostas por determinados ordenamentos jurídicos quanto ao grau de sua apropriação como um tipo de propriedade industrial ou sui generis-, dado que as inovações biotecnológicas, como importantes ativos empresariais, devem atender, também, aos ditames do interesse público da indisponibilidade do bem ambiental como fundamental para uma sadia qualidade de vida por meio do uso racional da biodiversidade.

Logo, exige-se uma maior participação da população, que deverá incluir não somente entidades não governamentais, mas também (mediante referendos) as populações que possam ser atingidas pelas medidas que estão em análise. Isto importa na obrigatoriedade do Estado em assegurar a essas populações o pleno conhecimento dos relatórios ambientais, como determinam os instrumentos internacionais, como o Protocolo de Kiev e a Convenção de Aarhus.

Pelo exposto, não se pode desprezar os pontos favoráveis que determinadas biotecnologias podem trazer para os produtores, os consumidores e, até mesmo, para o meio ambiente, devendo o jurista considerar todos esses aspectos na hora de avaliar a viabilidade de determinada tecnologia, ainda envolta por dúvidas suficientemente fundadas não somente numa precisão científica atual, sujeita a revisões pelo emprego de novas técnicas ou o desenvolvimento de novos equipamentos mais precisos, mas também no desejo que cada povo tem de desenvolver-se dentro de padrões culturais e de crenças nas suas relações com um meio ambiente preservado para as gerações presentes e futuras. E que cada povo, dentro de sua esfera da autodeterminação ecológica, tenha o direito de optar ou não pela adoção de determinadas inovações biotecnológicas ainda envolvidas em considerável grau de dúvidas quanto à sua biossegurança, inclusive para a conservação da própria biodiversidade nas lentes da sustentabilidade.

\section{Referências}

ALMEIDA, Alberto Francisco Ribeiro de. Denominação de origem e marca. Coimbra: Coimbra Editora, 1999.

ANJOS FILHO, Robério Nunes dos. O direito à autodeterminação dos povos indígenas: entre a secessão e o autogoverno. In: ANJOS FILHO, Robério Nunes dos (org.). Direitos humanos e direitos fundamentais: diálogos contemporâneos. Salvador: Juspodivm, 2013. p. 588-620.

ARAGÃO, Alexandra. Energia renovável sustentável: como superar o paradoxo energético. In: SILVA, Suzana Tavares da (org.). Estudos de direito da energia n. ${ }^{\circ}$ 0. Coimbra: Várzea da Rainha, 2014. p. 233-258.

ASCENSÃO, José de Oliveira. Sociedade da informação e mundo globalizado. Revista brasileira de direito comparado, Rio de Janeiro, n. 22, p. 161-182, jan./jun. 2002.

BRAGA, Tánia Moreira. Sustentabilidade e condições de vida em áreas urbanas: medidas e determinantes em duas regiões metropolitanas brasileiras. Revista Eure, Santiago, v. XXXII, n. 96, p. 47-71, ago. 2006.

CANOTILHO, José Joaquim Gomes. O princípio da sustentabilidade como princípio estruturante do Direito Constitucional. Tékhne: revista de estudos politécnicos, Barcelos, v. 8, n. 13, p. 7-18, 2010. 
CASTANHEIRA NEVES, A. O Direito hoje e com que sentido? O problema atual da autonomia do Direito. 3. ed. Lisboa: Instituto Piaget, 2012.

CORROZA, Hermenegildo Baylos. Tratado de derecho industrial: propriedad industrial, propriedad intelectual, derecho de la competencia economica, disciplina de la competencia desleal. 2. ed. Madrid: Editorial Civitas, 1993.

DIAS, Osmar. A trajetória político-parlamentar da biossegurança. In: COSTA, Marco Antonio F. da; COSTA, Maria de Fátima Barrozo da (org.). Biossegurança de OGM: uma visão integrada. Rio de Janeiro: Publit, 2009. p. 15-32.

FREITAS, Juarez. Teoria da regulação administrativa sustentável. Revista de Direito Administrativo, Rio de Janeiro, v. 270, p. 117-145, set./dez. 2015.

FREITAS, Joycemara Cristina Sales de. A auditoria externa ambiental como instrumento de defesa do meio ambiente. Revista Jurídica do Ministério Público do Estado de Minas Gerais, Belo Horizonte, v. 12, n. 20, p. 293-309, jan./jun. 2013.

GARDELLA, Mercè Darnaculleta. Derecho administrativo y autorregulación: la autorregulación regulada. 2002. Tesis (Doctorado) - Departament de Dret Públic, Universitat de Girona, Girona, 2002. Disponível em: http://www.tdx.cat/handle/10803/7681. Acesso em: 29 abr. 2018.

GRAY, A. J. The policy chicken and the science egg. Has applied ecologyy failed the Transgenic crops debate?. Transgenic Research, London, v. 23, n. 6, p. 923-932, dec. 2014.

HISSA, Cássio Eduardo Viana. Fronteiras da transdisciplinaridade moderna. In: HISSA, Cássio Eduardo Viana (org.). Saberes ambientais: desafios para o conhecimento disciplinar. Belo Horizonte: Editora UFMG, 2008. p. 15-32.

JUNQUEIRA, N. T. V. et al. A importância da polinização manual para aumentar a produtividade do maracujazeiro. Planaltina: Embrapa Cerrados, 2001.

MARICONDA, Pablo Rubén; RAMOS, Maurício de Carvalho. Transgênicos e ética: a ameaça à imparcialidade científica. Scientiae studia, São Paulo, v. 1, n. 2, p. 245-261, abr./jun. 2003.

MARQUES, João Paulo Fernandes Remédio. Propriedade intelectual e interesse público. Boletim da Faculdade de Direito de Coimbra, Coimbra, v. 79, p. 293-354, 2003.

MICHELS, Gilson Wessler. Tribunal Internacional do Direito do Mar. In: BARRAL, Welber (org.).

Tribunais internacionais: mecanismos contemporâneos de solução de controvérsias. Florianópolis:

Fundação Boiteux, 2004. p. 89-112.

MOREIRA NETO, Diogo de Figueiredo. De la ecología a la ecoideología. De la prevención a la precaucion. Revista de Administración Pública, Madrid, n. 186, p. 481-490, sep./dic. 2011.

PEIXOTO NETO, Pedro Accioly de Sá. O direito fundamental à propriedade industrial: uma análise à luz do desenvolvimento tecnológico e econômico. Revista Eletrônica Direito e Política, Itajaí, v. 8, n. 2, p. 1174-1201, 2013. Disponível: http://siaiap32.univali.br/seer/index.php/rdp/article/view/5476/2900. Acesso em: 20 jun. 2018.

PEIXOTO NETO, Pedro Accioly de Sá. Transgênicos: uma análise à luz dos princípios jurídicos da precaução e da segurança alimentar. Revista Brasileira de Políticas Públicas, Brasília, v. 4, n. 2, p. 131-156, jul./dez. 2014. Disponível em: https://www.publicacoesacademicas.uniceub.br/RBPP/article/ download/2777/pdf. Acesso em: 20 jun. 2018.

PEIXOTO NETO, Pedro Accioly de Sá. Propriedade intelectual em biotecnologia: um breve diálogo acerca da relação entre direito e a biotecnologia em face da inovação tecnológica. Actualidad Jurídica Iberoamericana, Valencia, n. 4, p. 226-240, feb. 2016. Disponível em: http://idibe.org/wp-content/ uploads/2013/09/9._Pedro_Accioly_pp._226-240.pdf. Acesso em: 20 jun. 2018.

PRUDENTE, Antônio Souza. Transgênicos, biossegurança e o princípio da precaução. Revista CEJ, Brasília, n. 25, p. 77-79, abr./jun. 2004.

SCAFF, Fernando Campos. Direito agrário: origens, evolução e biotecnologia. São Paulo: Atlas, 2012. 
EUROPEAN UNION. Europeans and biotechnology in 2010: winds of change? Luxembourg: Publications Office of the European Union, 2010. Disponível em: http://ec.europa.eu/research/sciencesociety/document_library/pdf_06/europeans-biotechnology-in-2010_en.pdf. Acesso em: 02 jun. 2018.

UNITED NATIONS. Simplified resource manual to support application of the protocol on strategic environmental assessment. New York e Geneva: United Nations Publications, 2012. Disponível em: http://www.apambiente.pt/_zdata/AAE/Enquadramento\%20Legislativo/Simplified_Resource_Manual_ AAE.pdf. Acesso em: 02 jun. 2018.

UNITED NATIONS. Protocol on strategic environmental assessment to the convention on Environmental impact assessment in a transboundary context. 2003. Disponível em: http://www. unece.org/fileadmin/DAM/env/eia/documents/legaltexts/protocolenglish.pdf. Acesso em: 02 jun. 2018.

WANDSCHEER, Clarissa Bueno. Patentes \& conhecimento tradicional: uma abordagem socioambiental da proteção jurídica do conhecimento tradicional. Curitiba: Juruá, 2009.

WOLFENBARGER, L. L.; PHIFER, P. L. The ecological risks and benefits of genetically engineered plants. Science, New York, v. 290, p. 2088-2093, Dec. 2000.

ZANELLA, Andréa Vieira. Sujeito e alteridade: reflexões a partir da psicologia histórico-cultural. Psicologia \& Sociedade, Porto Alegre, v. 17, n. 2, p. 99-104, maio/ago. 2005.

Enviado em: $21 / 08 / 2018$

Aprovado em: 19/02/2019 